Introduction: The Development of the International Round Table for the Advancement of Counselling

\title{
H. Z. HOXTER*
}

The need for counselling has become increasingly apparent in numerous industrial and developing countries over the period of the past twenty years. This demand for new forms of understanding of human needs is experienced equally by parents, educators, employers, medical and social workers and other groups concerned with problems and difficulties of contemporary society. In response there has developed a wide variety of counselling practice and thought. Amongst the various groups in need of counselling, young adults in the transition stage from school to work; educationally and socially disadvantaged persons; deprived, emotionally disturbed, disabled and delinquent children have stood out as potential groups of clients of this new counselling approach. A group of people from many parts of the world decided to set up a framework to encourage the international interchange of ideas between individuals and groups of counsellors through studies, information and research. From this arose the first meeting of the International Round Table. IRTAC continues to provide opportunities for men and women working in the field of counselling, or engaged in the training of counsellors, to meet together to learn from their respective experience. This is facilitated by the provision of discussion groups, seminars and conferences for members of many academic and professional groups. Counsellors are able to meet those of other disciplines interested in exploring new approaches to caring and helping; to pool ideas and to apply them to the counselling field.

IRTAC also promotes the publication of bulletins, journals and books related to the broad field of counselling.

IRTAC assists in offering advice and information to intergovernmental and non-gevernmental international organisations as well as national organisations, both in industrial and developing countries concerning all aspects of counselling developments and application.

It may be interesting to compare the place of counselling internationally at this time with the situation 12 years earlier at the time of the preparation of the first International Seminar of Counselling, which took place at Neuchâtel, Switzerland at the beginning of 1966 . This first international Counselling

* President, Executive Council of IRTAC. 
Consultation brought together some 80 distinguished persons from about 15 countries and was rightly seen as an innovatory pioneering venture.

The International Round Table for the Advancement of Counselling is today officially recognised by the Economic and Social Council of the United Nations; UNESCO: the International Labour Organisation; UNICEF and the Council of Europe and enjoys Consultative Statusrganisations.

Successful International Conferences and Seminars of Counselling have taken place in Neuchâtel, Switzerland, January, 1966; Salzburg, Austria, May, 1967; Turin, Italy, April, 1968; The Hague, Netherlands, April, 1970; Paris, France, July, 1972; Cambridge, United Kingdom, April, 1974; Würzburg, Germany, April, 1976. These seven International Round Tables of Counselling will be followed by the Eighth International Consultation which will take place within the University of Oslo at Oslo, Norway, during July, 1978, under the title - 'Challenges to Counselling from a Society in Change'. Recent Round Tables were attended by some 400 persons, representing the major International Organisations, some 45 countries and delegates of many developing countries.

The International Round Table has published reports of several of their Conferences under such headings as - "Counselling and Guidance of the Student in Higher Education'; 'The Social Implications of Counselling'; 'Counselling the Community and Society'.

However, at least as important as the activities of IRTAC on an international level has been the result in many regions and areas of the world. There can be little doubt that the activities of IRTAC have proved successful in drawing attention to the increasing need of counselling for children, young adults and adults alike and in numerous differing contexts obtained consideration in the programmes of international organisations and governments. This introductory article offers a welcome opportunity to express gratitude to UNESCO; the International Labour Organisation; ECOSOC; UNICEF and the Council in Europe for their constructive encouragement of and interest in the Counselling Movement. Without the active help of the Governments of Switzerland, Austria, Italy, the Netherlands, France, the United Kingdom and Bavaria, the International Conference could not have grown so fast either in importance or scope over the past twelve years. In addition, the support of the Bernard van Leer Foundation, of The Hague, Netherlands and of the Volkswagen Werk foundation of Hanover, Germany is acknowledged with gratitude.

Increasingly, over the past ten years the International Round Table for the Advancement of Counselling has gained recognition as an International 
Association with scientific and educational aims, concerned with the interdisciplinary study of counselling and guidance in academic and nonacademic fields. Membership of IRTAC is open to any person, association, institution or other body engaged in counselling and interested in its aims and objectives. The growth and position of IRTAC is due to the large number of dedicated members who have given devoted, generous service to its cause as members of the Council, editors of publications and consultants; it is a privilege to express deep gratitude to them all. Their activities have substantially contributed to the development and growth of the Counselling Movement the world over. It must be hoped that this latest initiative of launching the International Journal of Counselling will stimulate and mark a further important step forward in the advance, development and progress of the Counselling Movement. 